\title{
Electric Vehicles for Public Transportation in Power Systems: A Review of Methodologies
}

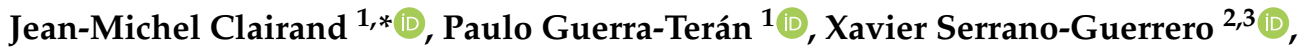 \\ Mario González-Rodríguez ${ }^{1,4}$ (D) and Guillermo Escrivá-Escrivá ${ }^{3}$ (D) \\ 1 Facultad de Ingeniería y Ciencias Agropecuarias, Universidad de las Américas-Ecuador, \\ Quito 170122, Ecuador \\ 2 Grupo de Investigación en Energías, Universidad Politécnica Salesiana, Cuenca 010103, Ecuador \\ 3 Institute for Energy Engineering, Universitat Politècnica de València, 46022 Valencia, Spain \\ 4 Intelligent \& Interactive Systems Lab ( $\left.\mathrm{SI}^{2} \mathrm{Lab}\right)$, Universidad de las Américas-Ecuador, \\ Quito 170125, Ecuador \\ * Correspondence: jean.clairand@udla.edu.ec; Tel.: +593-9-95860613
}

Received: 3 July 2019; Accepted: 9 August 2019; Published: 14 August 2019

\begin{abstract}
The market for electric vehicles (EVs) has grown with each year, and EVs are considered to be a proper solution for the mitigation of urban pollution. So far, not much attention has been devoted to the use of EVs for public transportation, such as taxis and buses. However, a massive introduction of electric taxis (ETs) and electric buses (EBs) could generate issues in the grid. The challenges are different from those of private EVs, as their required load is much higher and the related time constraints must be considered with much more attention. These issues have begun to be studied within the last few years. This paper presents a review of the different approaches that have been proposed by various authors, to mitigate the impact of EBs and ETs on the future smart grid. Furthermore, some projects with regard to the integration of ETs and EBs around the world are presented. Some guidelines for future works are also proposed.
\end{abstract}

Keywords: charging approaches; electric bus; electric taxi; electric vehicle; public transportation; smart grid

\section{Introduction}

Transportation is one of the sectors that is facing various challenges due to environmental concerns. These concerns include the depletion of fossil fuels, global warming, and local pollution. In this scenario, battery-powered electric vehicles (EVs) could be a proper solution to mitigate environmental issues $[1,2]$. These are wheeled vehicles that use an electric motor that is powered by a battery for propulsion. They must be recharged at home or at a public charging station, where three main levels of charging are used, depending mainly on the charge rate [3]. For the purposes of this paper, an EV will be a vehicle supplied with electricity from a battery, in order to differentiate from electric trains or trolleybuses, which are vehicles supplied with electricity directly from the grid by means of overhead wires.

In particular, EVs do not generate local pollution, and they have a well-to-wheel energy efficiency that is much more significant than that of internal combustion vehicles (ICVs). However, EVs present cradle-to-grave environmental impacts, especially due to the use of lithium batteries. The manufacturing phase corresponds to the highest environmental burden of EVs, mainly in the toxicity categories because of the use of metals in the battery pack [4]. To address these issues, it is crucial to minimize power losses in the battery and develop proper recycling tools [5]. Despite these issues, EVs can reduce $\mathrm{CO}_{2}$ emissions with most of the generation mix scenarios. If the electricity is generated only by coal plants, the well-to-wheel $\mathrm{CO}_{2}$ emissions of EVs are still similar to that of 
ICVs [6-8]. Therefore, several governments in different countries are promoting the purchase of EVs with economic incentives. The replacement of ICVs with EVs will offer the potential to significantly reduce greenhouse gas emissions.

Although EVs present several environmental advantages, a massive introduction of them could create several issues in the power grid, which has been studied by several researchers. For example, in [9], the impact of different penetration levels of plug-in EVs in a distribution system was considered, and it was demonstrated that a significant EV load leads to voltage drop and voltage deviations. A $30 \%$ plug-in EV integration in the grid led to a voltage deviation of $10.3 \%$ between $18 \mathrm{~h} 00-21 \mathrm{~h} 00$ in the winter period, in the studied case. In [10], it was demonstrated that charging EVs considerably increases the distribution load and, so, the total power losses. Furthermore, EV charging increases the daily peak load. The authors of [11] indicated that EVs generate substantial investment costs in distribution systems, and that power losses can reach up to $40 \%$ for an EV penetration of $62 \%$. In [12], it was exposed that EV fast charging leads to harmonic issues and failure to respect IEEE standard limits. In [13], it was proposed that the life durations of low-voltage transformers are reduced with a high penetration of EVs.

Considering all these issues, several researchers have widely studied strategies for the massive introduction of EVs into power systems. For example, smart charging of EVs is an important area of study, which allows EV users and grid operators to properly manage EV charging profiles in order to obtain technical and economic benefits, as well as considering the specific demand-side management of EVs [11]. Smart charging techniques include the Vehicle-to-Grid (V2G) concept, where the EV not only charges from the grid, but it supplies energy when necessary, becoming a generation/storage device [14,15]. For instance, investments in Renewable Energy Sources (RESs) for cleaner electricity production have also been related to EV integration into the grid. In particular, RES such as solar photovoltaic (PV) and wind create other challenges, due to their power generation uncertainties and fluctuations, as well as their high installation costs $[16,17]$.

Some other researchers have focused on the management of EV charging stations. In particular, it is crucial to locate the optimal placement of EV charging stations to meet technical grid constraints, considering customer wait times $[18,19]$. Another solution to mitigate EV impacts on the grid considers implementing smart chargers. These chargers are generally implemented off-board the EV and are connected by DC plug. They possess advanced communication capabilities to receive instructions from the grid operator, in order to take actions for the grid requirements. They are usually bidirectional to also supply electricity to the grid, enabling control options for distribution feeders [20-22].

On this basis, EV integration in the grid has widely been addressed in the literature. Various reviews have studied smart charging techniques, potentials, barriers, and technologies for EVs. For example, in [23], smart charging approaches, such as strategies, algorithms, methods, and projects, were presented. The authors of [24] reviewed the EV economic, environmental, and grid impacts, and the interactions between EVs and RESs. In [25], the main technical challenges for the integration of EVs into the grid were studied. The authors of [26-28] centered their review of V2G impacts, potentials, and limitations on RES integration with EVs. The challenges and opportunities for a Lithuanian case study were provided in [29]. In [30], optimization techniques for EV charging infrastructures, such as computational and algorithmic aspects, were analyzed. EV charging control and operation in power grids was studied in [31], considering issues related to the real-time EV charging in smart grids. Although EV integration into power systems has been appropriately studied in the literature, all these works (and others) have only addressed the issues relating to private EVs. To the knowledge of the authors, no work has yet reviewed the integration techniques in power systems for public transportation using EVs, which is the main objective of this work. In addition, it is necessary to understand the importance of the behavior of these new users, as their behavior in terms of schedules and demanded power is very different than that of private EVs.

So far, there has been scarce research in the literature on EVs for public transportation, such as taxis and buses. In particular, public transportation is crucial for modern societies with growing 
populations. Public transportation was defined as "a service provided by public or private agencies that is available to all persons who pay the prescribed fare" in [32]. Moreover, public transport has the following characteristics:

- Efficient mass transfer of passengers;

- Ease of access, such that any individual has the means to use public transport;

- Transport along an organized system of fixed routes; and

- Based on a pre-defined timetable, resulting in fixed intervals of transport along particular routes.

Generally, taxis meet the four conditions but, in several places, the first and third conditions are not met. Thus, the question of whether taxis are public transportation arises. However, this question is out of the topic, so ETs will be assumed as public transportation in this paper. Despite the environmental benefits of personal EVs, they may result in high congestion in urban areas, which creates another concern. Furthermore, even if EVs emit less pollutants than ICVs, they have a considerable footprint due to the required electricity generation. Investing in public transportation will considerably decrease $\mathrm{CO}_{2}$ emissions $[33,34]$, and will be more beneficial for the environment if the vehicles used are EVs. On the other hand, public transportation should also be electric for health reasons. It has been demonstrated that emissions from ICVs, especially from buses, create several health problems [35]. These problems have been shown to be worse, in terms of emissions, for high-elevation cities [36]. Therefore, central and local governments are pushing to promote EVs for public transportation. In terms of the aforementioned issue, it is crucial to improve the quality of the services offered by public transportation [37].

The challenges of using EVs for public transportation are much different from those of private EVs. Taxis travel much longer daily distances than an average private driver. Therefore, the daily energy needed to charge an electric taxi (ET) is much higher than a typical EV. Furthermore, as mentioned above, it is arguable that ETs are public transportation, because they do not have fixed routes and timetables, and these conditions must be taken into consideration. Electric buses (EBs) require high energy capacity batteries and, so, they will consume a significant amount of power during charging time, which will create an impact on the grid. These new issues must be adequately addressed by researchers, as well as transportation and energy players.

The aim of this paper is to review the different proposed approaches and tools used by researchers to study the impact of ETs and EBs in power systems. With this review, it is expected that researchers who are working on this topic could comprehend the state of the art and provide some insights into research gaps for future works.

The rest of this paper is organized as follows: Section 2 presents an overview of EVs for public transportation. Section 3 discusses the main approaches of integrating ETs and EBs into power systems. Section 4 presents some projects related to EV integration into public transportation. Section 5 provides some insights for future work. Finally, Section 6 highlights the main conclusions of the paper.

\section{Electric Vehicles for Public Transportation}

\subsection{Types of EVs}

As mentioned above, battery EVs are vehicles that are fully powered by a battery, in order to differentiate them from ICVs, hybrid EVs, and plug-in hybrid EVs. Typically, their distance range is much smaller than other kinds of vehicles, but they are much more efficient and environmentally friendly.

EVs are powered by electricity, which is stored in the battery. In addition, the configuration for both buses and sedans (for ETs) include auxiliary devices, an electric motor, a transmission system, and a final drive, as shown in Figure 1. 


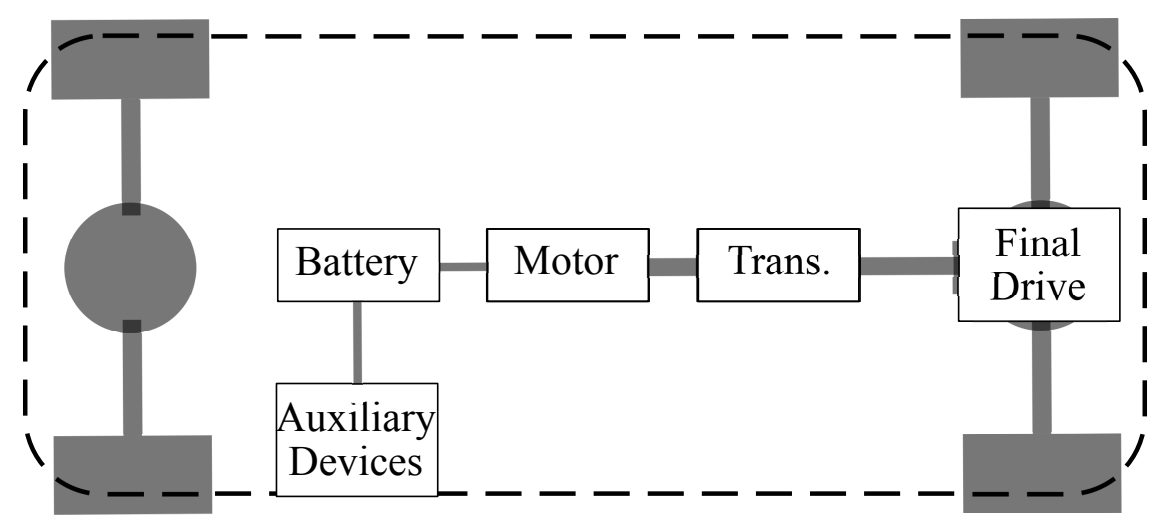

Figure 1. Electric Vehicle (EV) Configuration [38].

For private EVs, various models are sold in the market, such as the Nissan Leaf and Kia Soul EVs. However, these models may be not appropriate for taxis. In particular, the Nissan Leaf and Kia Soul have low distance ranges: $241 \mathrm{~km}$ for the Nissan Leaf and $179 \mathrm{~km}$ for the Kia Soul [39,40]. The most appropriate models for ETs considered by investors and researchers are the BYD e6 and the Tesla S [41,42], due to their higher battery capacities and distance ranges. The characteristics of these vehicles are summarized in Table 1.

For EBs, the brand BYD has produced various models and is the brand that has sold the most buses in the world [43]. In Europe, the most commercialized EBs are from Volvo and Solaris. Some of these models are, also, summarized in Table 1.

Table 1. Characteristics of EVs for public transportation [41-45].

\begin{tabular}{cccccc}
\hline Model & Use & Battery Capacity [kWh] & Charging Power [kW] & Range [km] & Charging Time [min] \\
\hline BYD e6 & Taxi & 80 & 40 & 400 & 120 \\
Tesla S & Taxi & 100 & $16.5 / 120$ & 480 & $420 / 42$ \\
BYD 23' Coach & Bus & 121 & 40 & 200 & 180 \\
BYD 40' Coach & Bus & 352 & $40 \times 2$ & 322 & 270 \\
BYD 60' Coach & Bus & 578 & 200 & 355 & 180 \\
Solaris Urbino 12 & Bus & 145 & $2 \times 125$ & 100 & 24 \\
Volvo 7900 & Bus & 76 & 300 & 200 & 15 \\
\hline
\end{tabular}

\subsection{Charging EVs for Public Transportation}

Charging systems are crucial components for the adoption of EVs in transportation. Charging EVs for public transportation is a key challenge, as mentioned above, because of the higher amount of required electrical energy for charging EV batteries, as well as the time requirements.

For ETs and EBs, three principal types of charging emerge: Plug-in charging, battery swapping, and wireless charging. These kinds of charging might be implemented in public charging stations, and must interact with power systems, the electricity market, and fleet operators, in order to meet their respective constraints. Power system constraints include power, voltage, and frequency limits. The electricity market provides electricity prices to optimize charging costs or, in some cases, electricity bids to participate in ancillary services. Fleet operator constraints include the schedules for EBs and ETs, which must be respected to guarantee passenger satisfaction. This interaction is depicted in Figure 2. 


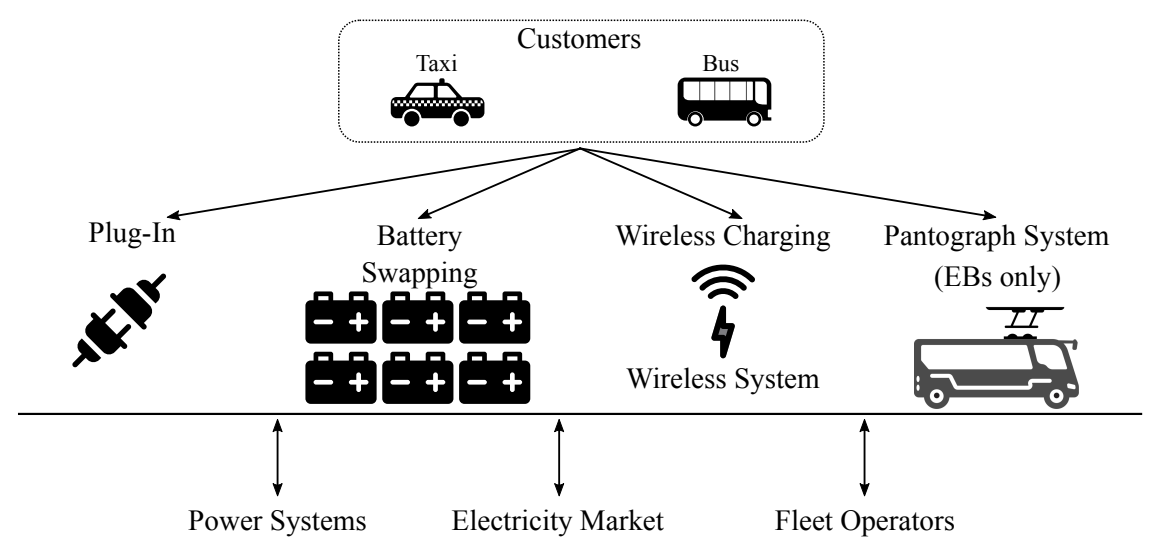

Figure 2. Interaction between EVs for public transportation and power systems.

\subsubsection{Plug-In Charging}

Plug-in charging corresponds to the most widely used method for charging EVs, especially for private ones. For small vehicles, such as ETs, three primary charging levels are used: Level 1, or slow charging, is the slowest charging, which is not recommended for EVs for public transportation, because of the time limitations. Level 2 requires a $240 \mathrm{~V}$ outlet and is the primary method for both public and private facilities. Level 3 requires a DC connection, and is the fastest solution for charging an EV battery, but requires a high amount of power over a small time duration [3]. These three levels are summarized in Table 2.

Table 2. Charging Power Levels [3].

\begin{tabular}{cccc}
\hline Power Level Types & Charger Location & Expected Power Level & Charging Time \\
\hline Level 1 & On-board, 1-phase & $1.9 \mathrm{~kW}(20 \mathrm{~A})$ & $11-36 \mathrm{~h}$ \\
Level 2 & On-board, 1- or 3-phase & $8 \mathrm{~kW}(32 \mathrm{~A}), 19.2 \mathrm{~kW}(80 \mathrm{~A})$ & $2-6 \mathrm{~h}$ \\
Level 3 & Off-board, 3-phase & $50 \mathrm{~kW}, 100 \mathrm{~kW}$ & $0.2-1 \mathrm{~h}$ \\
\hline
\end{tabular}

For EBs, it is not feasible to consider slow charging levels, as the battery capacity (around $400 \mathrm{kWh}$ ) is high and, so, charging could take very long, limiting trip schedules. Fast charging seems the best level option for both EBs and ETs, considering consumer convenience. However, this charging level presents issues: EV batteries heat up while being charged, large conductors and AC/DC converters are required, and electric utilities limit their use because the critical power required creates grid issues. Hence, these technical limitations have been the focus of study of some works [46]. Some of the alternatives consist of providing energy storage by distributed generation in a fast-charging station to mitigate peak loads on the grid.

\subsubsection{Wireless Charging System (WCS)}

In addition to the issues presented before, environmental conditions (e.g., rain, snow, and extreme temperatures) can cause discomfort for users when they connect an EV manually at the charging station. Moreover, failure of power cords and connectors can cause safety issues (risk of electrical sparking and electrical shock) [47]. Wireless charging systems (WCS) arise as a solution for the above problems. Furthermore, the main advantage of WCS is providing the opportunity for making fast and frequent charges while the EV is in transit; for example, in streets with heavy traffic, bus stops, parking lots, and so on. This possibility allows for battery downsizing with the following main benefits: (a) lighter weight EVs, (b) reduction of cost of the EV and repositioned batteries, (c) savings in energy due to a decrease in mass, and (d) reduction of $\mathrm{CO}_{2}$ emissions. For example, in [48], the authors concluded that a WCS, in comparison with a plug-in charging system, consumes $0.3 \%$ less energy and emits $0.5 \%$ fewer greenhouse gases. The WCS is a proven technology that provides an exciting alternative charging system, which has been used in several projects for city battery-powered buses [47]. The principal 
difference between a plug-in charging system and a WCS is that the second uses a pair of coupled coils or capacitors, instead of a transformer. The air-gap between the two coils or capacitors produces a leakage magnetic field that needs to be controlled for safety reasons [49]. Wireless charging has the following steps: First, a rectifier that converts the AC utility power to DC power; then, the DC power is converted to $\mathrm{AC}$ power of high frequency to drive the primary coil or capacitor by a compensation network. The electromagnetic field produced by the primary coil or capacitor induces an alternating voltage in the secondary coil or capacitor, transferring $\mathrm{AC}$ power that is then is rectified to charge the battery [49]. A WCS is depicted in Figure 3.

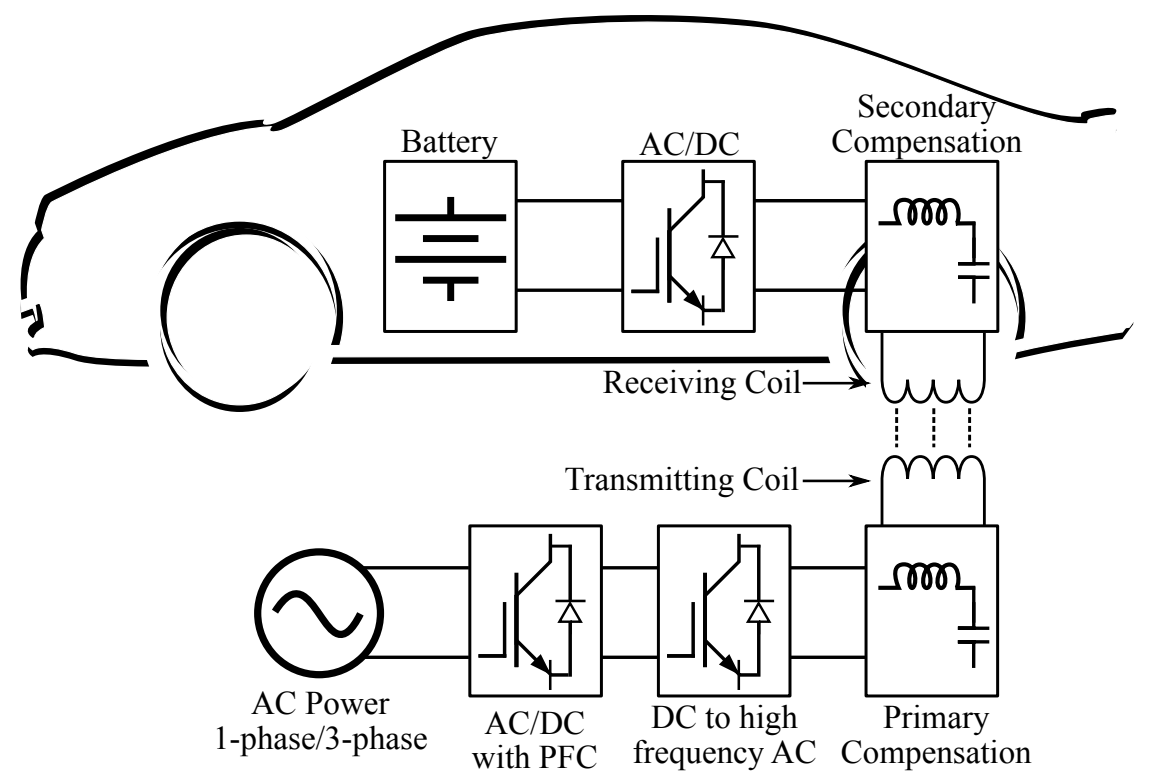

Figure 3. Wireless Charging system [49].

The literature shows that there are three main classifications of WCS that can be used for public buses: Capacitive wireless power transfer, inductive wireless power transfer, and resonant inductive power transfer [50,51].

The main advantages of WCSs include less energy consumption and less greenhouse gases emitted, compared to plug-in charging [48]. The challenges of this technology include low efficiency of energy transfer, due to losses during coil-to-coil transfer; high installation costs, which are significantly higher than plug-in charging; and human exposure to radio frequency radiation and magnetic fields [50].

\subsubsection{Battery Swapping Station (BSS)}

A Battery Swapping Station (BSS) is an EV station where customers can swap their discharged battery with a charged one [52]. It has begun to be adopted, especially for electrified public transportation. The BSS requires a high stock of batteries to supply its customers. Many works assume that the batteries are owned by the BSS and rented to the customers, which could be EB and ET companies. The main benefit of BSS for customers is that they can immediately have a charged battery, similar to gas stations. Moreover, the BSS generally provide benefits for the EV batteries, since their life is not affected when they are not charged at fast charging levels. This is possible when the amount of batteries owned by a BSS is high and, so, they have time flexibility to charge them.

The BSS commonly includes a vehicle platform, lift, alignment, and equipment rollers; battery lifts, conveyor shuttles, storage racks, and rails; and electrical connection alignments [53].

The electrical components of the BSS to charge the batteries include a distribution transformer, AC/DC chargers, battery packs, and a battery energy control module [53]. The transformer converts high voltage levels from the grid to a lower level, adapted to supply electricity to the batteries. 
Then, as the batteries require $\mathrm{DC}$ energy, the $\mathrm{AC} / \mathrm{DC}$ adapts the $\mathrm{AC}$ energy coming from the transformer. The control module allows charging at different power levels, depending on grid requirements. Some works have considered a bidirectional AC/DC converter, allowing V2G services.

One of the main advantages of BSSs is that a third party could own the batteries and be responsible for replacing them with fully charged ones, monitoring their health and decommissioning the batteries once they are no longer suitable. Moreover, the BSS offers time benefits to users, similar to typical gas stations, avoiding long wait times. The main limitations of BSS include standardization of EV battery packs, acceptance of the BSS model, and the reliable estimation of battery state-of-health. Furthermore, the question of whether BSS are profitable has been brought up in [53].

\subsubsection{Pantograph System}

A pantograph system is a solution that allows the EBs to charge quickly at stops, which has been the focus of various research studies. The pantograph system includes an automatic connecting system, DC-conductive charging supply equipment, fixed conductive rails attached to the roof of the vehicle, conductive poles, and communication systems [54]. The Automatic Connecting System controls and monitors a connection device for conductive charging fixed to the infrastructure above the vehicle. It includes an Automatic Connecting Device, which connects or disconnects EV supply conductive components to the vehicle interface. The DC EV conductive charging system provides a voltage in a range between $450-750 \mathrm{~V}$, allowing a power supply up to $450 \mathrm{~kW}$. A very well-known pantograph is the OPPCharge from ABB [55]. Figure 4 illustrates a pantograph system.

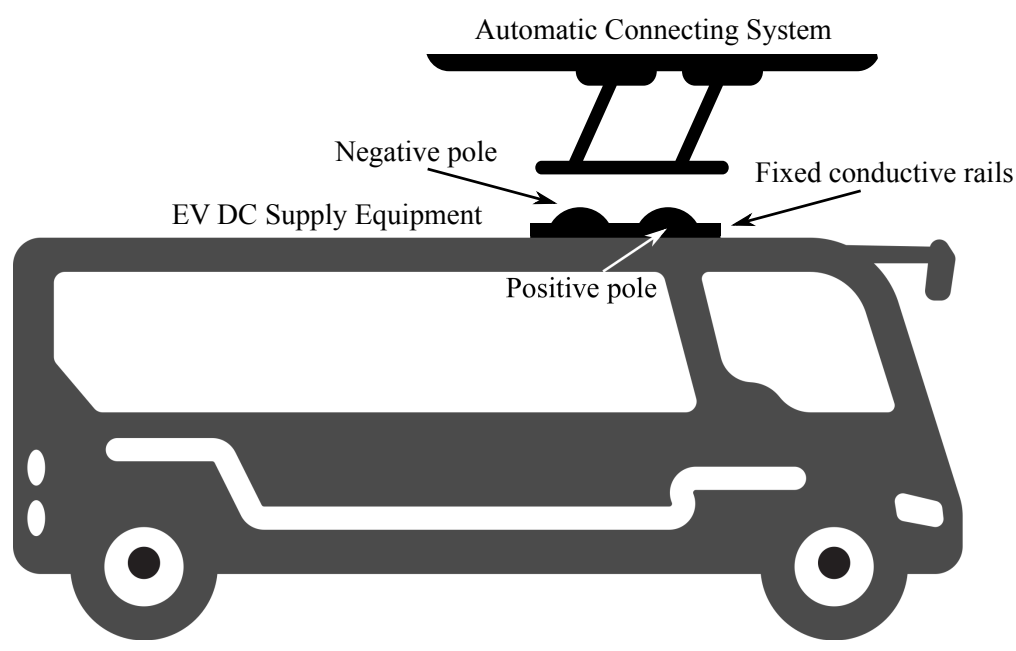

Figure 4. Pantograph System.

Even if several EB makers provide pantograph interfaces, BYD does not offer any pantograph system for their customers because their EBs have high distance range autonomy and can operate for an entire day, so only one daily charge for a few hours is required [56]. Moreover, so far, no research work has included pantographs in their approach.

\section{Impact of Electric Vehicles for Public Transportation in Power Systems}

The various approaches considering the introduction of EBs and ETs in Power Systems is a recent trend that has been studied by several researchers. Note that research in this field only began in 2014 . So far, the research in this area has been much smaller than that on the impact of private EVs on power systems. A search in SCOPUS was performed, finding separately the approaches for ETs, EBs, and the few approaches that considered both ETs and EBs. Therefore, all the research papers related to this topic were analyzed and are summarized here. In Figure 5, the number of peer-reviewed papers published by some countries on EB and ET integration into the grid is shown. It can be seen that China 
leads by far, in terms of paper production, followed by the USA. This can be explained by the fact that several real projects using ETs and EBs are being developed in various cities in China.

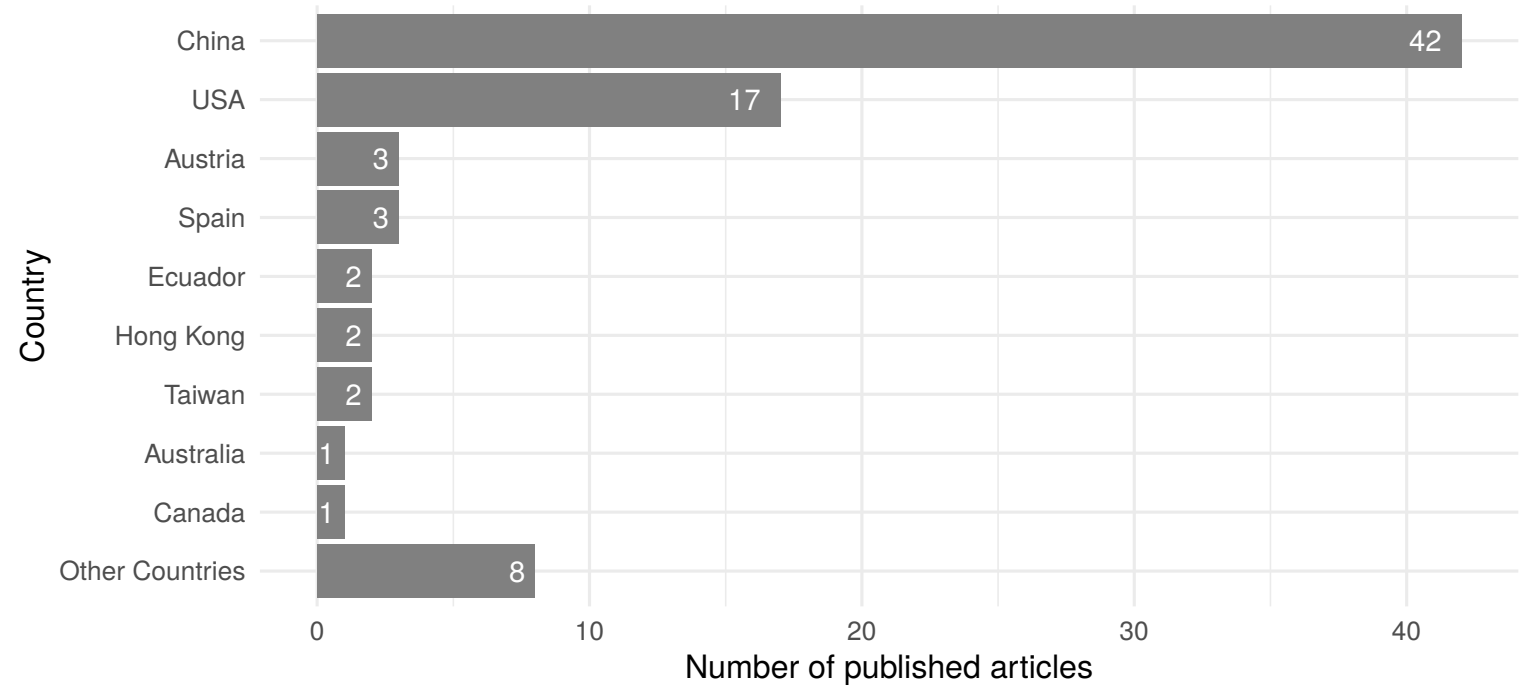

Figure 5. Number of published articles from different countries.

\subsection{Electric Taxis (ETs) Approaches}

In the literature, various methodologies for integrating electric taxis (ETs) into the grid can be found. Foremost, several researchers have studied the load prediction of ETs, in order to evaluate the impact on the grid. Thus, the authors of [57] proposed a precise charging load model for ETs based on multi-step $Q(\lambda)$ learning. In [58], the GPS measurements of 460 San Francisco taxis were used to estimate the charging load. Furthermore, an economic analysis was performed, demonstrating that an ET fleet would reduce the costs considerably, compared to an ICV fleet. In [59], the charging loads of ETs were studied, based on real data from the taxi charging data of 129 vehicles from Shenzhen, China. In [60], the distribution of ET charging demands were studied based on resident's travel characteristics. The authors of [61] studied the feasibility of a purely ET fleet, based on the ZENEM demonstration project in Vienna, Austria. The results demonstrated that the main issue of an ET fleet connected to the grid results in overloading, which needs to be appropriately managed by controlled charging. In [62], battery charging and swapping stations were modeled to compare their load impacts, demonstrating that EV fast charging generates more important peaks than swapping stations. The authors of [63] performed a realistic large-scale ET application in Beijing, based on the real in-use EV data to analyze fleet driver behavior, charging patterns, and energy consumption and efficiency. Note that the results were representative for this particular case study.

Some other works put focus on the charging station sites and sizing for ETs. Thus, in [64], a decision support system was studied for placing ET charging stations. The objective was to maximize charging demand satisfaction of ET drivers, based on the data of 800 taxi vehicles in Vienna. The authors of [65] exposed a data-driven optimization-based approach for siting and sizing ET charging stations. In this case, the objective was to minimize the charging infrastructure by using integer linear programming. The case study corresponded to Changsha, China, where data was obtained from the large-scale GPS trajectory of the taxi fleet. The results indicated that various candidate sites did not need to install chargers and that, allowing for a waiting time, the numbers of chargers can be significantly reduced. However, the authors do not account for the SOC when ETs arrive at charging station. Similarly, the optimal location of charging stations was presented in [66]. Their methodology was based on a multi-agent system to simulate plug-in hybrid ET daily operations, and minimized charging costs of plug-in ETs, power losses, and voltage deviations. The novelty of their approach was that taxi agents made decisions concerning whether to find passengers or to charge the plug-in ETs. Furthermore, this model included the participation of new agents for ETs, such as the 
time agent, the map agent, the passenger generator agent, the charging station agent, and plug-in ET agent. However, this methodology included a reward function that depended on the time for finding passengers, which could be feasible for this particular case study, but the behavior of ETs in the real world is significantly different and depends mostly on local laws. The authors of [67] considered the deployment of charging stations, considering the effects of passengers, taxi drivers, electricity retailers, the transportation and distribution networks, and power consumers. To solve the proposed model, a multi-objective optimization was proposed. In [68], the siting and sizing were determined based on the calculation of the radius of the charging station service.

Some other approaches considered the optimal ET plug-in charging station time usage. Thus, in [69], a multi-objective optimization was proposed to maximize the use efficiency of charging facilities, minimize the load unbalance (power losses), and minimize the customer cost, by use of a fuzzy mathematical method and improved particle swarm optimization algorithm. Data of Shenzhen was used to demonstrate the effectiveness of the methodology. The authors of [70] proposed a methodology that assists ET to charge more efficiently with respect to time. Actual data from eight charging stations in Shenzhen was used to simulate the proposed model. However, no conditions for the grid were considered.

Some attention has been paid to system costs. In [71], the charging costs were defined as the loss of service income caused by charging. A plug-in ET driver can choose the ideal time slot to charge, considering the SOC, time-varying income, and queuing status at charging stations. Cost minimization was obtained through a game-theoretic approach, and this method demonstrated that it is also possible to enhance the use ratio for charging stations, and to flatten the unevenness of charging request for power grids. The authors of [72] studied the interaction between a fleet of self-driving EVs, which can be considered to be ETs, and the grid. A joint model that captured the coupling between the EV charging requirements, capturing time-varying customer demand, battery depreciation, and grid transmission constraints, was considered. A Texas case study was proposed, demonstrating the effectiveness of the model. The results indicated that system costs were reduced.

Focusing on BSSs, it is crucial to develop methodologies to maximize the daily operation profits. Thus, the authors of [73] proposed a linear programming model by considering constraints on the battery swapping demand of users and charging state of batteries. A real case study from the ETs in Beijing was used to prove the effectiveness of the methodology.

Some approaches have focused on minimizing the costs of BSSs. For example, the authors of [74] presented a Smart Battery Charging and Swapping Operation Service Network for both particular EVs and ETs. The methodology was based on the State Grid Corporation of China, which consists of providing battery swapping as the primary service (complemented by typical charging, if necessary). A model based on Queuing theory was proposed to minimize the overall cost of station operations, considering that most of the taxis charge 3 or 4 times per day, with a fast charging time of $46 \mathrm{~min}$. A case study in Hangzhou, China, was proposed to demonstrate the effectiveness of the methodology. Another example was performed by [75]. A Monte Carlo method and the Dijkstra Algorithm were adopted to simulate electric taxi operations. Then, an optimization model was proposed to minimize the costs of the BSS. In [76], a real-time battery scheduling problem was proposed. The strategy was evaluated using the data set of routes in the city of Suzhou, China. In the same line, the authors of [77] proposed a methodology that minimizes electricity costs, battery degradation, and low battery use. The problem was solved by convex optimization with both spatially and temporally coupled constraints.

Real-Time pricing has also been adopted as a methodology. In [78], the profit maximization of a plug-in ET was investigated, considering the uncertainties of electricity prices and time-varying incomes, which was solved by a thresholding method. The results demonstrated improvements in profits compared to common strategies. The authors of [79] studied the optimal charging problem to maximize the average profit of a plug-in ET in the long-term, considering SOC dynamics constraints. The optimization problem is infinite binary and was solved by dividing it into a series of periodic sub-problems. The proposed method demonstrated better performance than other algorithms, such as 
stochastic strategy. In [80], real-time pricing was proposed for regulating the collective charging load of the ET fleet. This could induce the taxi fleet to modify its charging decisions. However, the charging depended on taxi drivers and, so, the fluctuation of charging prices could not be used and the high prices for charging in peak periods could not be ignored.

The massive introduction of ETs also creates economic challenges. Therefore, the cost-effectiveness of investments must be studied. In particular, the question concerning charging or battery changing for ETs arises. Hence, in [81], the long-term planning for ET introduction has been studied by comparing battery swapping and battery charging models in the Pinggu District of Beijing. The results indicated that for this particular case study, the battery swapping model was economically better than the battery charging model, but a high level of technology must be considered. The authors of [82] proposed a MILP optimization to minimize the investments and operation costs of ET charging stations, considering the constraints of the service radius of charging stations, charging demand satisfaction, and rational occupation rate of chargers.

Another novelty concerning typical EVs is the use of taxi apps. Taxi apps allow for the finding of customers, which reduces empty cruising distance. It has also been considered that taxi apps will enable drivers to find the closest charging stations, with real-time information about charging availability. The authors of [83] demonstrated that taxi apps reduce taxi trip distances and, therefore that they can reduce energy consumption for EVs.

The analyzed ET strategies are summarized in Table 3, and the tools used in Table 4.

Table 3. Main Objectives of ET-related Papers.

\begin{tabular}{cc}
\hline Main Objectives & References \\
\hline ET Load prediction & {$[57-63]$} \\
Siting and sizing of ET charging stations & {$[64-68]$} \\
Optimal plug-in charging station time usage & {$[69,70]$} \\
Minimized Costs of ET plug-in charging stations & {$[71,72]$} \\
Maximization of Profit of BSS & {$[73]$} \\
Minimized Costs of BSSs & {$[74-77]$} \\
Minimized Load Unbalance & {$[69]$} \\
Minimized Customer Cost & {$[69]$} \\
Real-Time Pricing (decentralized) & {$[78-80]$} \\
Planning ET charging stations & {$[81,82]$} \\
Taxi Apps & {$[83]$} \\
\hline
\end{tabular}

Table 4. Tools used.

\begin{tabular}{cc}
\hline Tools Used & References \\
\hline Method & \\
\hline Integer Linear Programming & {$[65]$} \\
Linear Programming & {$[73]$} \\
Multi-Objective Optimization & {$[66,67,69]$} \\
MILP Optimization & {$[64,82]$} \\
Convex Optimization & {$[77]$} \\
Particle Swarm Optimization & {$[69,70]$} \\
Binary programming & {$[79]$} \\
Game-theoretic approach & {$[71]$} \\
Heuristic Method & {$[76,84]$} \\
\hline
\end{tabular}

\subsection{Electric Bus (EB) Approaches}

Several researchers have studied the load prediction of EBs. For example, in [85], the forecasting of EB BSS was proposed, based on stochastic modeling. The charging load model used statistical data of the travel patterns of EBs. The hourly number of EBs, starting charging time, travel distance, and charging duration were considered to be crucial variables for the forecast and were modeled 
through prediction methods, such as neural networks, uniform distributions, and the Gaussian model. A Monte Carlo method and a kernel density estimator were used for handling the uncertainties. The authors of [86] studied the modeling of EB buses in a full transit network, based on a real-time simulation model considering the real-world transit constraints of Belleville, Ontario, Canada. Moreover, the impact of the grid has been analyzed, such as the impacts on the lifetimes of substation transformers and the voltage regulation and voltage control devices. The results indicated that EB loads reduce transformer lifetimes considerably and generate voltage issues. In [87], short-term forecasting was studied for EB charging stations. This forecasting was based on a hybrid model, which combines fuzzy clustering, a least squares support vector machine, and the wolf pack algorithm (WPA). To demonstrate the accuracy of the forecasting, two case studies were proposed, demonstrating high precision.

Some approaches have focused on minimizing the charging costs of EB fast-charging stations. In [88], a methodology that reduced the total costs of investments and charging costs was presented. This work considered the value of energy storage in an EB fast-charging station, demonstrating that energy storage contributes to the reduction of long-term costs. The problem was solved by a mixed integer non-linear programming formulation, considering the capital costs of the transformer, distribution feeder, and energy storage constraints. The authors of [89] proposed a charging strategy for fast-charging stations based on a decision-making process, which considered that the EBs only charge when the SOC is below a charging threshold at the fast charger. This strategy was simulated using a case study of Tallahassee, Florida, demonstrating cost reductions compared to cases without charging strategies. In [90], real-time coordinated charging strategies for EB fast-charging stations were proposed. The purpose of this was to minimize power purchase costs, considering the daily Time-of-Use prices, and the peak loads were also mitigated. This work was complemented by [91], where an additional energy storage system was included, and the problem formulation was more complete. A heuristic method was used, considering whether the plug-in EBs were controllable or not. The method was simulated in Chongqing, China, validating the importance of the energy storage in EB charging stations.

Minimizing costs of EB BSSs has also been considered by some authors. In [92], the operational costs of an EB BSS were minimized. For this, the EB load was forecasted, based on a fuzzy evaluation and through actual survey data. The charging costs were optimized based on a Genetic Algorithm optimization approach and considering Time-of-Use prices. The case study of Baoding, Hebei province, China was evaluated, indicating an improvement in the profits with normal conditions. In the same line, the authors of [93] minimized the cost of a BSS with distributed PV.

Focusing on charging stations, it is essential to study their allocation. In this aspect, the deployment of EB charging stations has been considered in [94]. A bi-objective optimization was used to minimize both the number of charging stations and the EB stop time. For this, based on a discrete event simulation, the EB energy consumption was evaluated, taking into account load and friction forces, as well as different data from a case study of Curitiba, Brazil, such as passenger demand, bus, speed, distances, and route elevation profiles. The authors of [95] studied the planning decisions for siting and sizing EB charging stations. For this, an optimization charging scheduling framework was developed, which minimized the annual system operating costs, including a recharging wait cost as a penalty term. This problem was solved by a MILP and applied to a case study of the city of Davis, California, USA. Moreover, it has been demonstrated that EBs are more economical, compared to diesel buses. In the same line, in [96], the siting and sizing of fast-charging stations were proposed, considering energy consumption uncertainty. The model minimized system costs subject to electric and bus constraints. The problem was solved by a MILP with the GAMS software, and a robust optimization was applied to tackle the energy uncertainty. It was applied to the Salt Lake City (USA) bus system.

Economic planning has been another objective for some authors. In [97], the planning and operation of an EB charging station were studied, based on a Time-of-Use pricing scheme. The long-term planning model considered minimizing the energy costs, considering the operational constraints of a 
bus company of Taiwan and using the data from the Taiwan Power Co. The authors of [98] examined the long-term planning of three different power supply systems: wireless charging, battery swapping, and plug-in charging. The analysis was performed in Daegu City, South Korea. The results showed that investing in battery swapping stations was more beneficial than the other options for single and composite routes. Similarly, the three different power supply system costs were analyzed in [99], but considering only investment costs. The objective was to search for optimal design models by minimizing costs. Several parameters relative to EB circulation were analyzed, resulting in different investment costs for each case. In the same line, ref. [100] presented the long-term planning of EB fast-charging stations,

Considering load aggregation and renewable integration. The model optimized the investment planning and operation schedule of the EB system, based on a MILP formulation. Furthermore, an aggregation strategy was considered for co-ordination with PV resources and energy storage, considering bus route constraints. The uncertainties were tackled through Chance-constrained programming. A two-stage stochastic program for the BSS location problem to minimize the investment and operation costs was proposed in [101]. The case of Melbourne, Australia, was studied.

Another exciting approach considers the scheduling of a wirelessly charged EB system, as presented in [102]. For this, an optimal methodology that minimizes system electricity costs was developed, considering the characteristics of the WCS. The problem was solved by convex optimization, and it was demonstrated in the Guangzhou (China) Bus Rapid Transit system. Note that this methodology is considered to be a constraint to passenger satisfaction, which is associated with the passenger wait time and bus crowdedness.

By integrating large amounts of EBs into the grid, it is also crucial to maintian proper power quality levels in the network. In particular, a significant EB load leads to voltage drops. Hence, ref [103] proposed an energy management system for a smart public transportation network to regulate voltage levels. This system included solar plants and energy storage devices at EB stops. To control the energy flows, an fuzzy logic controller was used. The model was illustrated in the electrified transportation network in Guwahati City, India, showing proper voltage profiles and, thus, avoiding grid issues.

Considering the electric market transactions, the operation of EBs in the framework of Virtual Power Plants can be considered. Hence, in [104], the profit maximization of a Virtual Power Plant integrating EBs was considered by enabling the provision of grid services. Based on MILP optimization, the problem was solved considering energy procurement constraints, and proving the opportunity for EBs and Virtual Power Plants to jointly provide grid services.

The analyzed EB strategies are summarized in Table 5, and the tools used in Table 6.

Table 5. Main Objectives of EB-related Papers.

\begin{tabular}{cc}
\hline Main Objectives & References \\
\hline EB Load Prediction & {$[85-87]$} \\
Minimized costs of EB charging stations & {$[88-91]$} \\
Minimized cost of EB BSSs & {$[92,93,101]$} \\
Siting and sizing of EB charging stations & {$[94-96]$} \\
Minimized EB stop time & {$[94]$} \\
Planning EB charging stations & {$[97-101]$} \\
Minimized system costs of a wireless charged EB system & {$[102]$} \\
Voltage regulation & {$[103]$} \\
Profit Maximization of Virtual Power Plant & {$[104]$} \\
\hline
\end{tabular}


Table 6. Tools used.

\begin{tabular}{cc}
\hline Tools Used & References \\
\hline Mixed Integer Non-Linear Programming & {$[88]$} \\
Multi-objective optimization & {$[94]$} \\
MILP & {$[90,95,100]$} \\
Heuristic method & {$[90,91,105]$} \\
Genetic Algorithm Optimization & {$[92]$} \\
Fuzzy Logic & {$[103]$} \\
\hline
\end{tabular}

\subsection{Approaches of Both Electric Taxis and Buses}

As the operation of ETs and EBs generally require different needs, only a few studies have considered the both ETs and EBs. These works considered general aspects of their combined integration, such as the electrical load, environmental elements, and economic costs. These works are described in this section.

Some authors have considered the effect of smart charging techniques. In [106], the potential and economics of EB and ET smart charging were studied, focusing on the case of Shanghai, China. It was concluded that the possibilities for EB and ET smart charging are different and that a specific charging tariff with a high peak-valley price gap is compulsory to obtain benefits from EV smart charging. The authors of [107] proposed a charging strategy for both EBs and ETs for isolated systems with high penetration of renewable generation. Based on the proposed pricing, which maximized renewable generation use, the methodology optimized the charging load of EBs and ETs in the case study of Santa Cruz, Galapagos Islands, Ecuador. The results demonstrated that it is possible to increase the renewable generation use for EV charging, compared to uncoordinated charging. Another example of the minimization of charging cost was presented in [105], where the system load profile was also optimized and satisfied use charging requirements. The problem was solved by quadratic optimization. Case studies of Guangdong Province, China were performed, demonstrating system peak demand and charging cost reduction.

Another work which focused on both EBs and ETs dealt with BSSs. This choice must be seriously considered for EVs that require both significant electric energy consumption over a day and small time duration for charging. Therefore, the authors of [108] studied battery and charger planning for battery switch stations, minimizing investments, maintenance, and electricity costs.

Deploying ETs and EBs generates a new load that must be met by the power generation system. Thus, the question of optimal generation mix arises, considering the emissions involved. In [109], the environmental effects of ETs and EBs were considered in Beijing, indicating a reduction of millions of kilograms of $\mathrm{CO}_{2}$ would result if they were deployed. Then, the power generation structure was analyzed. In a micro-grid case, the authors of [110] presented power generation planning considering the integration of EBs and ETs. For this purpose, the charging loads of EBs and ETs for different scenarios were modeled to obtain the optimal generation portfolio. This study was performed in the Micro-grid of Santa Cruz, Ecuador, and the results demonstrated that the best option resulted from investing in new PV generation.

\section{Electric Vehicles for Public Transportation Projects over the World}

Various projects have been developed around the world for electrifying public transportation. These projects have included the deployment of EVs in public transportation in cities. Some of the most relevant projects are listed as follows:

- The Green eMotion project is a European project with a budget of $€ 42$ million. It is part of the European Green Cars Initiative (EGCI) that was launched within the context of the European Recovery Plan. It is composed of 42 partners from industry, the energy sector, EV manufacturers, 
municipalities, universities, and research institutions. Although this project has focused primarily on private EVs, some works have been done with ETs in Ireland [111].

- The Smart Electric Bus (BEI) project in the city of Vitoria-Gasteiz, Spain. It was the first all-electric zero emissions line of Vitoria-Gasteiz and Euskadi. This transport system was implemented by the companies Irizar e-mobility, Yarritu, and LKS, and was composed of a fleet of 13 EBs [112].

- The NEXT-E project represents a co-operation of four leading companies from the electricity and oil and gas sectors with OEMs (car manufacturers) to create an inter-operable and non-discriminatory EV charging network. The project objective was to address the issues of a continuous and cost-effective network which could allow long-distance and cross-border driving. The NEXT-E project was funded with $€ 18.84$ million to implement the project [113].

- CIVITAS is a project whose aim is to propose alternative sustainable options for transportation. It was launched by the European Commission in 2002 and funded by the European Union. The project is complemented and supported by several research and innovation projects (ECCENTRIC, PORTIS, and DESTINATIONS) [114].

- Within the ELCIDIS project, seven European cities and CITELEC co-operate, together with the European Association of cities interested in the use of EVs. This project was created to demonstrate the possibilities of a more efficient city distribution system that works with clean EVs (hybrids). The projects of the cities of Rotterdam and Stockholm focus on the deployment of large electric vans. The city project in La Rochelle focuses on deploying EVs with a payload of approximately $500 \mathrm{~kg}$. The projects of the city of Stavanger, Milan, and Erlangen will focus on the deployment of hybrid EVs for the internal distribution of goods and mail for companies [115].

- In Santiago de Chile, Metbus is one of the largest pure EB fleet operators in Latin America . The project seeks to reach 3500 EBs. Currently, the projected fleet is 411 Chilean EBs, and the brands of the EBs are BYD and Yutong. EBs can accommodate up to 38 passengers each. The range, according to the manufacturer, is $250 \mathrm{~km}$ and the operational costs have been reduced by $76 \%$, compared to traditional buses [116].

- The 16,359 public buses of Shenzhen are now electric. A new law passed in 2017, requires that from 2018, all buses providing transport services for passengers within Shenzhen must be electric. It is prohibited to use internal combustion buses. The measure applies to both public service buses and private buses. With this law, Shenzhen expects to reduce its emissions by up to 1.35 million tons of $\mathrm{CO}_{2}$ per year. This is a project of 490 million dollars, which was obtained by government subsidies and the companies responsible for the assembly of the electrical infrastructure and the manufacture of buses.

- In Pengcheng, the partners have some incentives, such as a free commercial operation license for 12 years for each E-taxi of the municipality of Shenzhen. Furthermore, the Shenzhen municipality exempts customers of an E-taxi from paying a fossil fuel surcharge. The charging stations for the E-taxi fleet were jointly built by Pengcheng, BYD, and CSG [117].

- A research project named EMIL ("E-Mobility using inductive charging") in the city of Braunschweig. There are already five inductive charging stations for EB charging. The main goals are the conceptual design and the required measurements to charge ETs on the proprietary EMIL charging stations, considering the development of a system that can be applied to a variety of different vehicles [118].

- Amsterdam Airport Schiphol and the surrounding area are part of the Amstelland-Meerlanden concession, which will include 258 EBs by 2021 and has a value of around EUR 100 million per year. Schiphol Airport financed and built the infrastructure for the charging points on the Schiphol grounds. The EBs operate 24/7 and have a battery capacity of $170 \mathrm{kWh}$ [119].

- The purpose of the TransLink demonstration project is to guide the installation and operation of overhead charging stations for EBs in Vancouver. The Government of Canada has encouraged the widespread adoption of EVs by supporting projects which provide more options for sustainable transportation, demonstrating new and innovative charging technologies. The Government has invested \$182.5 million to support the deployment of electric chargers, natural gas and hydrogen 
refueling stations, and the development of standards. New Flyer Industries and Nova Bus are developing electric transit buses, while $\mathrm{ABB}$ and Siemens are developing the chargers. The project to evaluate inter-operability and performance will integrate more than one bus manufacturer and more than one charging system provider [120].

- The capital of Ukraine, Kiev, has a project where electric mobility is emerging as a solution for service vehicles, approximately 30 Nissan Leafs. On average, each car travels about $100 \mathrm{~km}$ per load and requires four load cycles per day. The company that owns the vehicles has reached an agreement with a fast-charging infrastructure operator and serves approximately 20 locations in Kiev, and each driver has a smart card that is used to pay at charging station [121].

- In Poland, the implementation of a national e-mobility strategy, including electric public transport and the related infrastructure, is currently backed by approximately $€ 2.3$ billion worth of governmental financial incentives for the period 2018-2028, mainly supported by the Low-Emission Transport Fund, and the Emission-Free Public Transport (BTP) program, as well as the European Structural and Investment Funds. Currently, around 189 EBs are operating in Polish cities, with an additional 390 vehicles that will be incorporated by the end of 2019 [122].

\section{Future Trends}

This section provides some insights for future research works related to the impact of ETs and EBs in the smart grid. As mentioned above, the number of works in this area is relatively small and recent, so future outlooks are described.

\subsection{ET and EB Aggregator}

The EV aggregator is a new player in the electricity market, which collects EVs by attracting and retaining them as a significant load that can beneficially impact the grid. The size of aggregation is crucial to ensure its proper role. An EV aggregator could work as a controllable load or as a resource [15].

The works considering EB or ET aggregators are few. Only the works [103,104] proposed an ET aggregator and the works [78,79] an EB aggregator. Furthermore, it should be noted that in various works, the BSS has been considered to be an entity that works as an aggregator, considering that it aggregates all batteries that are charged daily, and could offer services for the grid.

\subsection{Micro-Grids with RES and ETs or EBS}

Several works have considered using EVs as support for the integration of RES into the grid. However, in the main grids, RES are already integrated into the grid constraints and electricity markets. One interesting topic that has been increasing in popularity is the study of the operation of micro-grids with RES.

A micro-grid is described as a cluster of loads, distributed generation units, and energy storage systems, operated in co-ordination to reliably supply electricity, either connected to a host power system at the distribution level at a single point of connection or in isolation from the bulk grid. Moreover, a micro-grid can operate in grid-connected and stand-alone modes, depending on grid conditions and the transitions between these two modes [123].

Some remote communities or islands located far away from a mainland depend on isolated micro-grids based on diesel fuel, which is environmentally harmful [124]. These effects are even worse if pristine and protected environments are considered [110]. Therefore, micro-grids with RES are being developed, creating concerns for micro-grid stability due to the RES generation uncertainties and fluctuations. ETs and EBs seem to be a suitable solution for providing clean transportation, as well as to mitigate micro-grid stability issues with the use of their batteries as energy storage.

Only $[107,110]$ have addressed the impact of electric public transportation on a micro-grid with RES. It should be that expected more future works will emerge in this field. 


\section{3. $V 2 G$ for EBS and ETS}

V2G is considered to be a technique where EVs do not only absorb electricity from the grid, but can also supply electricity to the grid from their batteries, when the grid requires it [14]. V2G can offer four different services to the grid: baseload power, peak power, spinning reserves, and ancillary services. The last two have been considered to be ancillary services [14].

This trend has widely been studied for private EVs. As EBs and ETs possess higher-capacity batteries, V2G could be implemented for BSSs. In particular, BSSs could have time flexibility concerning WSS and plug-in fast charging.

Only [73] have considered V2G for an ET BSS. No work has considered V2G for EBs BSS. Therefore, this could be an insight for future research.

\section{Conclusions}

EVs will play a key role in the future smart grid, and are necessary for the reduction of polluting gases in cities. In particular, more attention has been devoted in the past few years to the introduction of EVs for public transportation. To achieve an adequate mass introduction of these EVs, it is essential to propose approaches that mitigate grid issues and improve power systems stability. Therefore, various methodologies have been established in the literature recently. In this paper, a review of different approaches for the integration of EVs for public transportation into power systems has been presented.

First, a brief background of the typical models used for ETs and EBs was presented. In particular, EVs for public transportation generally possess batteries with higher battery capacities than typical private EVs, and a bigger distance range. The four different types of charging were, then, introduced (plug-in charging, WCS, BSS, and pantograph).

The various works covered a broad range of objectives for ETs and EBs, such as siting and sizing charging stations, cost minimization, load unbalance minimization, planning of charging stations, and so on. Many of these works used optimization methods to solve their problems.

Several governments and organizations around the world are promoting the adoption of EVs by deploying pilot studies for the use of ETs and EBs, which were presented in this review.

Finally, this paper provides some insights for future research in this area, such as the interaction of ETs and EBs with aggregators, their integration into micro-grids with RES, and their participation in V2G services.

Author Contributions: Conceptualization, J.-M.C.; Data curation, J.-M.C., P.G.-T., and X.S.-G.; Formal analysis, J.-M.C.; Investigation, J.-M.C., P.G.-T., and X.S.-G.; Methodology, J.-M.C.; Supervision, M.G.-R. and G.E.-E.; Validation, M.G.-R. and G.E.-E.; Writing—original draft, J.-M.C., P.G.-T., and X.S.-G.; Writing—review and editing, J.-M.C., M.G.-R., and G.E.-E.

Funding: This research was funded by the project SIS.JCG.19.03 of Universidad de las Américas, Ecuador.

Conflicts of Interest: The authors declare no conflict of interest.

\section{Abbreviations}

The following abbreviations are used in this manuscript:

$\begin{array}{ll}\text { BSS } & \text { Battery Swapping Station } \\ \text { EB } & \text { Electric Bus } \\ \text { ET } & \text { Electric Taxi } \\ \text { EV } & \text { Electric Vehicle } \\ \text { ICV } & \text { Internal Combustion Vehicle } \\ \text { MILP } & \text { Mixed Integer Linear Programming } \\ \text { PV } & \text { Photovoltaic } \\ \text { RES } & \text { Renewable Energy Source } \\ \text { V2G } & \text { Vehicle-to-Grid } \\ \text { WCS } & \text { Wireless Charging System }\end{array}$




\section{References}

1. Emadi, A. Transportation 2.0. IEEE Power Energy Mag. 2011, 9, 54-64. [CrossRef]

2. Fahimi, B.; Kwasinski, A.; Davoudi, A.; Balog, R.S.; Kiani, M. Charge It! IEEE Power Energy Mag. 2011, 9, 54-64. [CrossRef]

3. Yilmaz, M.; Krein, P.T. Review of charging power levels and infrastructure for plug-in electric and hybrid vehicles. IEEE Trans. Power Electron. 2012, 28, 2151-2169. [CrossRef]

4. Tagliaferri, C.; Evangelisti, S.; Acconcia, F.; Domenech, T.; Ekins, P.; Barletta, D.; Lettieri, P. Life cycle assessment of future electric and hybrid vehicles: A cradle-to-grave systems engineering approach. Chem. Eng. Res. Des. 2016, 112, 298-309. [CrossRef]

5. Zackrisson, M.; Fransson, K.; Hildenbrand, J.; Lampic, G.; O’Dwyer, C. Life cycle assessment of lithium-air battery cells. J. Clean. Prod. 2016, 135, 299-311. [CrossRef]

6. Wu, Y.; Yang, Z.; Lin, B.; Liu, H.; Wang, R.; Zhou, B.; Hao, J. Energy consumption and $\mathrm{CO}_{2}$ emission impacts of vehicle electrification in three developed regions of China. Energy Policy 2012, 48, 537-550. [CrossRef]

7. Shen, W.; Han, W.; Chock, D.; Chai, Q.; Zhang, A. Well-to-wheels life-cycle analysis of alternative fuels and vehicle technologies in China. Energy Policy 2012, 49, 296-307. [CrossRef]

8. Wang, R.; Wu, Y.; Ke, W.; Zhang, S.; Zhou, B.; Hao, J. Can propulsion and fuel diversity for the bus fleet achieve the win-win strategy of energy conservation and environmental protection? Appl. Energy 2015, 147, 92-103. [CrossRef]

9. Clement-Nyns, K.; Haesen, E.; Driesen, J. The impact of Charging plug-in hybrid electric vehicles on a residential distribution grid. IEEE Trans. Power Syst. 2009, 25, 371-380. [CrossRef]

10. Shafiee, S.; Fotuhi-Firuzabad, M.; Rastegar, M. Investigating the impacts of plug-in hybrid electric vehicles on power distribution systems. IEEE Trans. Smart Grid 2013, 4, 1351-1360. [CrossRef]

11. Pieltain Fernández, L.; Gómez San Román, T.; Cossent, R.; Mateo Domingo, C.; Frías, P. Assessment of the impact of plug-in electric vehicles on distribution networks. IEEE Trans. Power Syst. 2011, 26, 206-213. [CrossRef]

12. Lucas, A.; Bonavitacola, F.; Kotsakis, E.; Fulli, G. Grid harmonic impact of multiple electric vehicle fast charging. Electr. Power Syst. Res. 2015, 127, 13-21. [CrossRef]

13. Turker, H.; Bacha, S.; Chatroux, D.; Hably, A. Low-voltage transformer loss-of-life assessments for a high penetration of plug-in hybrid electric vehicles (PHEVs). IEEE Trans. Power Deliv. 2012, 27, 1323-1331. [CrossRef]

14. Kempton, W.; Tomić, J. Vehicle-to-grid power fundamentals: Calculating capacity and net revenue. J. Power Sources 2005, 144, 268-279. [CrossRef]

15. Guille, C.; Gross, G. A conceptual framework for the vehicle-to-grid ( V2G ) implementation. Energy Policy 2009, 37, 4379-4390. [CrossRef]

16. Geng, Z.; Conejo, A.J.; Chen, Q.; Xia, Q.; Kang, C. Electricity production scheduling under uncertainty: Max social welfare vs. min emission vs. max renewable production. Appl. Energy 2017, 193, 540-549. [CrossRef]

17. Verbruggen, A.; Fischedick, M.; Moomaw, W.; Weir, T.; Nadaï, A.; Nilsson, L.J.; Nyboer, J.; Sathaye, J. Renewable energy costs, potentials, barriers: Conceptual issues. Energy Policy 2010, 38, 850-861. [CrossRef]

18. Oda, T.; Aziz, M.; Mitani, T.; Watanabe, Y.; Kashiwagi, T. Mitigation of congestion related to quick charging of electric vehicles based on waiting time and cost-benefit analyses: A japanese case study. Sustain. Cities Soc. 2018, 36, 99-106. [CrossRef]

19. Arkin, E.M.; Carmi, P.; Katz, M.J.; Mitchell, J.S.; Segal, M. Locating battery charging stations to facilitate almost shortest paths. Discret. Appl. Math. 2019, 254, 10-16. [CrossRef]

20. Gallardo-Lozano, J.; Milanés-Montero, M.I.; Guerrero-Martínez, M.A.; Romero-Cadaval, E. Electric vehicle battery charger for smart grids. Electr. Power Syst. Res. 2012, 90, 18-29. [CrossRef]

21. Aziz, M.; Oda, T.; Ito, M. Battery-assisted charging system for simultaneous charging of electric vehicles. Energy 2016, 100, 82-90. [CrossRef]

22. Mehboob, N.; Restrepo, M.; Canizares, C.A.; Rosenberg, C.; Kazerani, M. Smart Operation of Electric Vehicles with Four-Quadrant Chargers Considering Uncertainties. IEEE Trans. Smart Grid 2018, 10, 2999-3009. [CrossRef] 
23. García-Villalobos, J.; Zamora, I.; San Martín, J.I.; Asensio, F.J.; Aperribay, V. Plug-in electric vehicles in electric distribution networks: A review of smart charging approaches. Renew. Sustain. Energy Rev. 2014, 38, 717-731. [CrossRef]

24. Richardson, D.B. Electric vehicles and the electric grid: A review of modeling approaches, Impacts, and renewable energy integration. Renew. Sustain. Energy Rev. 2013, 19, 247-254. [CrossRef]

25. Haidar, A.M.; Muttaqi, K.M.; Sutanto, D. Technical challenges for electric power industries due to grid-integrated electric vehicles in low voltage distributions: A review. Energy Convers. Manag. 2014, 86, 689-700. [CrossRef]

26. Mwasilu, F.; Justo, J.J.; Kim, E.K.; Do, T.D.; Jung, J.W. Electric vehicles and smart grid interaction: A review on vehicle to grid and renewable energy sources integration. Renew. Sustain. Energy Rev. 2014, 34, 501-516. [CrossRef]

27. Habib, S.; Kamran, M.; Rashid, U. Impact analysis of vehicle-to-grid technology and charging strategies of electric vehicles on distribution networks-A review. J. Power Sources 2015, 277, 205-214. [CrossRef]

28. Tan, K.M.; Ramachandaramurthy, V.K.; Yong, J.Y. Integration of electric vehicles in smart grid: A review on vehicle to grid technologies and optimization techniques. Renew. Sustain. Energy Rev. 2016, 53, 720-732. [CrossRef]

29. Raslavičius, L.; Azzopardi, B.; Keršys, A.; Starevičius, M.; Bazaras, Ž.; Makaras, R. Electric vehicles challenges and opportunities: Lithuanian review. Renew. Sustain. Energy Rev. 2015, 42, 786-800. [CrossRef]

30. Rahman, I.; Vasant, P.M.; Singh, B.S.M.; Abdullah-Al-Wadud, M.; Adnan, N. Review of recent trends in optimization techniques for plug-in hybrid, and electric vehicle charging infrastructures. Renew. Sustain. Energy Rev. 2016, 58, 1039-1047. [CrossRef]

31. Faddel, S.; Al-Awami, A.T.; Mohammed, O.A. Charge control and operation of electric vehicles in power grids: A review. Energies 2018, 11, 701. [CrossRef]

32. Vuchic, V.R. Urban Transit Systems and Technology; John Wiley \& Sons: Hoboken, NJ, USA, 2007.

33. Ercan, T.; Onat, N.C.; Tatari, O. Investigating carbon footprint reduction potential of public transportation in United States: A system dynamics approach. J. Clean. Prod. 2016, 133, 1260-1276. [CrossRef]

34. Kwan, S.C.; Hashim, J.H. A review on co-benefits of mass public transportation in climate change mitigation. Sustain. Cities Soc. 2016, 22, 11-18. [CrossRef]

35. Kolbe, K. Mitigating urban heat island effect and carbon dioxide emissions through different mobility concepts: Comparison of conventional vehicles with electric vehicles, hydrogen vehicles and public transportation. Transp. Policy 2019, 80,1-11. [CrossRef]

36. Zalakeviciute, R.; Rybarczyk, Y.; López-Villada, J.; Diaz Suarez, M.V. Quantifying decade-long effects of fuel and traffic regulations on urban ambient PM2.5 pollution in a mid-size South American city. Atmos. Pollut. Res. 2018, 9, 66-75. [CrossRef]

37. Dell'Olio, L.; Ibeas, A.; Cecin, P. The quality of service desired by public transport users. Transp. Policy 2011, 18, 217-227. [CrossRef]

38. Mahmoud, M.; Garnett, R.; Ferguson, M.; Kanaroglou, P. Electric buses: A review of alternative powertrains. Renew. Sustain. Energy Rev. 2016, 62, 673-684. [CrossRef]

39. Nissan. Nissan Leaf. Available online: https://www.nissan.co.uk/vehicles/new-vehicles/leaf/rangecharging.html (accessed on 30 June 2019).

40. Kia. Introducing the Fully Charged 2020 Kia Soul EV. Available online: https://www.kia.com/us/en/ content/vehicles/upcoming-vehicles/2020-soul-ev (accessed on 30 June 2019).

41. BYD. e6. Available online: https:/ / en.byd.com/wp-content/uploads/2017/06/e6_cutsheet.pdf (accessed on 30 June 2019).

42. Tesla. Tesla Model S. Available online: https://www.tesla.com/models (accessed on 30 June 2019).

43. BYD. Bus. Available online: https:/ / en.byd.com/bus/40-electric-motor-coach/ (accessed on 30 June 2019).

44. Solaris. Urbino Electric. 2019. Available online: https://www.solarisbus.com/en/vehicles/zero-emissions/ urbino-electric (accessed on 24 July 2019).

45. Volvo. Volvo 7900 Electric. Available online: https://www.volvobuses.co.uk/en-gb/our-offering/buses / volvo-7900-electric/specifications.html (accessed on 24 July 2019).

46. Collin, R.; Miao, Y.; Yokochi, A.; Enjeti, P.; von Jouanne, A. Advanced Electric Vehicle Fast-Charging Technologies. Energies 2019, 12, 1839. [CrossRef] 
47. Yang, Y.; El Baghdadi, M.; Lan, Y.; Benomar, Y.; Van Mierlo, J.; Hegazy, O. Design methodology, modeling, and comparative study of wireless power transfer systems for electric vehicles. Energies 2018, 11, 1716. [CrossRef]

48. Bi, Z.; Song, L.; De Kleine, R.; Mi, C.C.; Keoleian, G.A. Plug-in vs. wireless charging: Life cycle energy and greenhouse gas emissions for an electric bus system. Appl. Energy 2015, 146, 11-19. [CrossRef]

49. Li, S.; Mi, C.C. Wireless power transfer for electric vehicle applications. IEEE J. Emerg. Sel. Top. Power Electron. 2015, 3, 4-17. [CrossRef]

50. Eberle, W.; Musavi, F. Overview of wireless power transfer technologies for electric vehicle battery charging. IET Power Electron. 2013, 7, 60-66. [CrossRef]

51. Wang, Z.; Wei, X.; Dai, H. Design and control of a $3 \mathrm{~kW}$ wireless power transfer system for electric vehicles. Energies 2016, 9, 10. [CrossRef]

52. Sarker, M.R.; Pandžić, H.; Ortega-Vazquez, M.A. Optimal operation and services scheduling for an electric vehicle battery swapping station. IEEE Trans. Power Syst. 2015, 30, 901-910. [CrossRef]

53. Adegbohun, F.; von Jouanne, A.; Lee, K.Y. Autonomous battery swapping system and methodologies of electric vehicles. Energies 2019, 12, 667. [CrossRef]

54. OPPCharge. OPPChargeCommon Interface for Automated Charging of Hybrid Electric and Electric Commercial Vehicles. 2019. Available online: https:/ / www.oppcharge.org/dok/OPPChargeSpecification2ndedition20190421. pdf (accessed on 24 July 2019).

55. OPPCharge. Fast Charging of Electric Vehicles. 2019. Available online: https://www.oppcharge.org (accessed on 24 July 2019).

56. Ruoff, C. The inevitability of electric buses. Charged 2016, 40-51.

57. Jiang, C.X.; Jing, Z.X.; Cui, X.R.; Ji, T.Y.; Wu, Q.H. Multiple agents and reinforcement learning for modelling charging loads of electric taxis. Appl. Energy 2018, 222, 158-168. [CrossRef]

58. Fraile-Ardanuy, J.; Castano-Solis, S.; Álvaro-Hermana, R.; Merino, J.; Castillo, Á. Using mobility information to perform a feasibility study and the evaluation of spatio-temporal energy demanded by an electric taxi fleet. Energy Convers. Manag. 2018, 157, 59-70. [CrossRef]

59. Rao, R.; Cai, H.; Xu, M. Modeling electric taxis' charging behavior using real-world data. Int. J. Sustain. Transp. 2018, 12, 452-460. [CrossRef]

60. He, Z.; Cheng, Y.; Hu, Z. Multi-Time Simulation of Electric Taxicabs' Charging Demand Based on Residents' Travel Characteristics. In Proceedings of the 2017 IEEE Conference on Energy Internet and Energy System Integration (EI2), Beijing, China, 26-28 November 2017; pp. 5-10.

61. Litzlbauer, M. Technische Machbarkeitsanalyse einer rein elektrisch betriebenen TaxiflotteTechnical feasibility study of a purely electrically driven taxi fleet. Elektrotech. Inf. 2015, 132, 172-177. [CrossRef]

62. Liao, B.; Li, L.; Li, B.; Mao, J.; Yang, J.; Wen, F.; Salam, M.A. Load modeling for electric taxi battery charging and swapping stations: Comparison studies. In Proceedings of the 2016 IEEE 2nd Annual Southern Power Electronics Conference (SPEC), Auckland, New Zealand, 5-8 December 2016; p. 150DUMMY. [CrossRef]

63. Zou, Y.; Wei, S.; Sun, F.; Hu, X.; Shiao, Y. Large-scale deployment of electric taxis in Beijing: A real-world analysis. Energy 2016, 100, 25-39. [CrossRef]

64. Asamer, J.; Reinthaler, M.; Ruthmair, M.; Straub, M.; Puchinger, J. Optimizing charging station locations for urban taxi providers. Transp. Res. Part A Policy Pract. 2016, 85, 233-246. [CrossRef]

65. Yang, J.; Dong, J.; Hu, L. A data-driven optimization-based approach for siting and sizing of electric taxi charging stations. Transp. Res. Part C Emerg. Technol. 2017, 77, 462-477. [CrossRef]

66. Jiang, C.; Jing, Z.; Ji, T.; Wu, Q. Optimal location of PEVCSs using MAS and ER approach. IET Gener. Transm. Distrib. 2018, 12, 4377-4387. [CrossRef]

67. Pan, A.; Zhao, T.; Yu, H.; Zhang, Y. Deploying Public Charging Stations for Electric Taxis: A Charging Demand Simulation Embedded Approach. IEEE Access 2019, 7, 17412-17424. [CrossRef]

68. Lianfu, C.; Zhang, W.; Huang, Y.; Zhang, D. Research on the charging station service radius of electric taxis. In Proceedings of the 2014 IEEE Conference and Expo Transportation Electrification Asia-Pacific (ITEC Asia-Pacific), Beijing, China, 31 August-3 September 2014; pp. 1-4. [CrossRef]

69. Yang, Y.; Zhang, W.; Niu, L.; Jiang, J. Coordinated Charging Strategy for Electric Taxis in Temporal and Spatial Scale. Energies 2015, 8, 1256-1272. [CrossRef]

70. Niu, L.; Zhang, D. Charging Guidance of Electric Taxis Based on Adaptive Particle Swarm Optimization. Sci. World J. 2015, 2015, 354952. [CrossRef] 
71. Yang, Z.; Guo, T.; You, P.; Hou, Y.; Qin, S.J. Distributed Approach for Temporal-Spatial Charging Coordination of Plug-in Electric Taxi Fleet. IEEE Trans. Ind. Inform. 2018, 15, 3185-3195. [CrossRef]

72. Rossi, F.; Iglesias, R.D.; Alizadeh, M.; Pavone, M. On the interaction between Autonomous Mobility-onDemand systems and the power network: Models and coordination algorithms. IEEE Trans. Control Netw. Syst. 2019, 5870, 1-12. [CrossRef]

73. Liang, Y.; Zhang, X.; Xie, J.; Liu, W. An Optimal Operation Model and Ordered Charging/Discharging Strategy for Battery Swapping Stations. Sustainability 2017, 9, 700. [CrossRef]

74. Xu, X.; Yao, L.; Zeng, P. Architecture and performance analysis of a smart battery charging and swapping operation service network for electric vehicles in China. J. Mod. Power Syst. Clean Energy 2015, 3, 259-268. [CrossRef]

75. Jing, Z.; Fang, L.; Lin, S.; Shao, W. Modeling for electric taxi load and optimization model for charging/ swapping facilities of electric taxi. In Proceedings of the 2014 IEEE Conference and Expo Transportation Electrification Asia-Pacific (ITEC Asia-Pacific), Beijing, China, 31 August-3 September 2014; pp. 1-5. [CrossRef]

76. Wang, Y.; Ding, W.; Huang, L.; Wei, Z.; Liu, H.; Stankovic, J.A. Toward Urban Electric Taxi Systems in Smart Cities: The Battery Swapping Challenge. IEEE Trans. Veh. Technol. 2018, 67, 1946-1960. [CrossRef]

77. You, P.; Yang, Z.; Zhang, Y.; Low, S.H.; Sun, Y. Optimal Charging Schedule for a Battery Switching Station Serving Electric Buses. IEEE Trans. Power Syst. 2016, 31, 3473-3483. [CrossRef]

78. Yang, Z.; Sun, L.; Chen, J.; Yang, Q.; Chen, X.; Xing, K. Profit maximization for plug-in electric taxi with uncertain future electricity prices. IEEE Trans. Power Syst. 2014, 29, 3058-3068. [CrossRef]

79. Yang, Z.; Sun, L.; Ke, M.; Shi, Z.; Chen, J. Optimal charging strategy for plug-in electric taxi with time-varying profits. IEEE Trans. Smart Grid 2014, 5, 2787-2797. [CrossRef]

80. Yang, J.; Xu, Y.; Yang, Z. Regulating the Collective Charging Load of Electric Taxi Fleet via Real-Time Pricing. IEEE Trans. Power Syst. 2017, 32, 3694-3703. [CrossRef]

81. Du, R.; Liao, G.; Zhang, E.; Wang, J. Battery charge or change, which is better? A case from Beijing, China. J. Clean. Prod. 2018, 192, 698-711. [CrossRef]

82. Chen, H.; Jia, Y.; Hu, Z.; Wu, G.; Shen, Z.J.M. Data-driven planning of plug-in hybrid electric taxi charging stations in urban environments: A case in the central area of Beijing. In Proceedings of the 2017 IEEE PES Innovative Smart Grid Technologies Conference Europe (ISGT-Europe), Torino, Italy, 26-29 September 2017.

83. Yang, J.; Dong, J.; Lin, Z.; Hu, L. Predicting market potential and environmental benefits of deploying electric taxis in Nanjing, China. Transp. Res. Part D Transp. Environ. 2016, 49, 68-81. [CrossRef]

84. You, P.; Low, S.H.; Yang, Z.; Zhang, Y.; Fu, L. Real-time recommendation algorithm of battery swapping stations for electric taxis. In Proceedings of the 2016 IEEE Power and Energy Society General Meeting (PESGM), Boston, MA, USA, 17-21 July 2016; pp. 1-5. [CrossRef]

85. Dai, Q.; Cai, T.; Duan, S.; Zhao, F. Stochastic modeling and forecasting of load demand for electric bus battery-swap station. IEEE Trans. Power Deliv. 2014, 29, 1909-1917. [CrossRef]

86. Mohamed, M.; Farag, H.; El-Taweel, N.; Ferguson, M. Simulation of electric buses on a full transit network: Operational feasibility and grid impact analysis. Electr. Power Syst. Res. 2017, 142, 163-175. [CrossRef]

87. Zhang, X. Short-term load forecasting for electric bus charging stations based on fuzzy clustering and least squares support vector machine optimized by Wolf pack algorithm. Energies 2018, 11, 1449. [CrossRef]

88. Ding, H.; Hu, Z.; Song, Y. Value of the energy storage system in an electric bus fast charging station. Appl. Energy 2015, 157, 630-639. [CrossRef]

89. Qin, N.; Gusrialdi, A.; Paul Brooker, R.; T-Raissi, A. Numerical analysis of electric bus fast charging strategies for demand charge reduction. Transp. Res. Part A Policy Pract. 2016, 94, 386-396. [CrossRef]

90. Chen, H.; Hu, Z.; Xu, Z.; Li, J.; Zhang, H.; Xia, X.; Ning, K.; Peng, M. Coordinated charging strategies for electric bus fast charging stations. In Proceedings of the 2016 IEEE PES Asia-Pacific Power and Energy Engineering Conference (APPEEC), Xi'an, China, 25-28 October 2016; pp. 1174-1179. [CrossRef]

91. Chen, H.; Hu, Z.; Zhang, H.; Luo, H. Coordinated charging and discharging strategies for plug-in electric bus fast charging station with energy storage system. IET Gener. Transm. Distrib. 2018, 12, 2019-2028. [CrossRef]

92. Gao, Y.; Guo, S.; Ren, J.; Zao, Z.; Ehsan, A.; Zheng, Y. An Electric Bus Power Consumption Model and Optimization of Charging Scheduling Concerning Multi-External Factors. Energies 2018, 11, 2060. [CrossRef] 
93. Cheng, Y.; Tao, J. Optimization of A Micro Energy Network Integrated with Electric Bus Battery Swapping Station and Distributed PV. In Proceedings of the 2018 2nd IEEE Conference on Energy Internet and Energy System Integration (EI2), Beijing, China, 20-22 October 2018; pp. 1-6. [CrossRef]

94. Sebastiani, M.T.; Luders, R.; Fonseca, K.V.O. Evaluating Electric Bus Operation for a Real-World BRT Public Transportation Using Simulation Optimization. IEEE Trans. Intell. Transp. Syst. 2016, 17, 2777-2786. [CrossRef]

95. Wang, Y.; Huang, Y.; Xu, J.; Barclay, N. Optimal recharging scheduling for urban electric buses: A case study in Davis. Transp. Res. Part E Logist. Transp. Rev. 2017, 100, 115-132. [CrossRef]

96. Liu, Z.; Song, Z.; He, Y. Planning of Fast-Charging Stations for a Battery Electric Bus System under Energy Consumption Uncertainty. Transp. Res. Rec. 2018. [CrossRef]

97. Leou, R.C.; Hung, J.J. Optimal charging schedule planning and economic analysis for electric bus charging stations. Energies 2017, 10, 483. [CrossRef]

98. Bak, D.B.; Bak, J.S.; Kim, S.Y. Strategies for implementing public service electric bus lines by charging type in Daegu Metropolitan City, South Korea. Sustainability 2018, 10, 3386. [CrossRef]

99. Chen, Z.; Yin, Y.; Song, Z. A cost-competitiveness analysis of charging infrastructure for electric bus operations. Transp. Res. Part C Emerg. Technol. 2018, 93, 351-366. [CrossRef]

100. Cheng, Y.; Wang, W.; Ding, Z.; He, Z. Electric bus fast charging station resource planning considering load aggregation and renewable integration. IET Renew. Power Gener. 2019, 13, 1132-1141. [CrossRef]

101. An, K.; Jing, W.; Kim, I. Battery-swapping facility planning for electric buses with local charging systems. Int. J. Sustain. Transp. 2019, 1-13. [CrossRef]

102. Yang, C.; Lou, W.; Yao, J.; Xie, S. On Charging Scheduling Optimization for a Wirelessly Charged Electric Bus System. IEEE Trans. Intell. Transp. Syst. 2018, 19, 1814-1826. [CrossRef]

103. Bhaskar Naik, M.; Kumar, P.; Majhi, S. Smart public transportation network expansion and its interaction with the grid. Int. J. Electr. Power Energy Syst. 2019, 105, 365-380. [CrossRef]

104. Raab, A.F.; Lauth, E.; Strunz, K.; Göhlich, D. Implementation schemes for electric bus fleets at depots with optimized energy procurements in virtual power plant operations. World Electr. Veh. J. 2019, 10, 5. [CrossRef]

105. Xu, Z.; Su, W.; Hu, Z.; Song, Y.; Zhang, H. A hierarchical framework for coordinated charging of plug-in electric vehicles in China. IEEE Trans. Smart Grid 2016, 7, 428-438. [CrossRef]

106. Jian, L.; Yongqiang, Z.; Hyoungmi, K. The potential and economics of EV smart charging: A case study in Shanghai. Energy Policy 2018, 119, 206-214. [CrossRef]

107. Clairand, J.M.; Rodríguez-García, J.; Álvarez-Bel, C. Electric Vehicle Charging Strategy for Isolated Systems with High Penetration of Renewable Generation. Energies 2018, 11, 3188. [CrossRef]

108. Liu, N.; Lin, X.; Chen, Q.; Zou, F.; Chen, Z. Optimal Configuration for Batteries and Chargers in Battery Switch Station Considering Extra Waiting Time of Electric Vehicles. J. Energy Eng. 2016, 143, 04016035. [CrossRef]

109. Ma, Y.; Ke, R.Y.; Han, R.; Tang, B.J. The analysis of the battery electric vehicle's potentiality of environmental effect: A case study of Beijing from 2016 to 2020. J. Clean. Prod. 2017, 145, 395-406. [CrossRef]

110. Clairand, J.M.; Arriaga, M.; Cañizares, C.; Alvarez-bel, C. Power Generation Planning of Galapagos' Microgrid Considering Electric Vehicles and Induction Stoves. IEEE Trans. Sustain. Energy 2018, 1-12. [CrossRef]

111. GreeneMotion. Green eMotion. Available online: http://www.greenemotion-project.eu/home/home.php (accessed on 28 June 2019).

112. Econoticias. El Bus Eléctrico Inteligente que funcionará en Vitoria a partir de 2020. Available online: https: / / www.ecoticias.com/motor/195107/Bus-Electrico-Inteligente-funcionara-Vitoria-partir-2020 (accessed on 28 June 2019).

113. Next-e. Available online: https:/ / next-e.eu/about.html (accessed on 28 June 2019).

114. Civitas. CIVITAS: Cleaner and Better Transport in Cities. Available online: https://civitas.eu/ (accessed on 28 June 2019).

115. Elcidis. The Elcidis Project. Available online: https://www.elcidis.org/project.htm (accessed on 28 June 2019).

116. Revista Colectibondi. Las principales flotas y proyectos con buses eléctricos alrededor del mundo. Available online: http:/ / www.revistacolectibondi.com.ar/2019/04/21/las-principales-flotas-y-proyectoscon-buses-electricos-alrededor-del-mundo/ (accessed on 28 June 2019). 
117. Li, Y.; Zhan, C.; de Jong, M.; Lukszo, Z. Business innovation and government regulation for the promotion of electric vehicle use: Lessons from Shenzhen, China. J. Clean. Prod. 2016, 134, 371-383. [CrossRef]

118. Henke, M.; Dietrich, T.H. High power inductive charging system for an electric taxi vehicle. In Proceedings of the 2017 IEEE Transportation Electrification Conference and Expo (ITEC), Chicago, IL, USA, 22-24 June 2017; pp. 27-32. [CrossRef]

119. Schiphol. Europe's Largest Fleet. Available online: https://www.schiphol.nl/en/schiphol-group/page/ europes-largest-fleet-of-fully-electric-buses / (accessed on 28 June 2019).

120. Government of Canada. Electric Bus Infrastructure Comes to Vancouver. Available online: https://www.canada. ca/en/natural-resources-canada/news/2018/04/electric-bus-infrastructure-comes-to-vancouver.html (accessed on 28 June 2019).

121. Destinations. Green Electric Cars in Oxy-Taxi Service in Kiev. Available online: https:/ / destinations.com. ua/cars-boats / green-electric-cars-in-oxy-taxi-service-in-kiev (accessed on 28 June 2019).

122. Bayer. Electric Mobility-Materials. Available online: http://www.research.bayer.com/en/23-electricmobility.pdf (accessed on 28 June 2019).

123. Olivares, D.E.; Mehrizi-Sani, A.; Etemadi, A.H.; Cañizares, C.A.; Iravani, R.; Kazerani, M.; Hajimiragha, A.H.; Gomis-Bellmunt, O.; Saeedifard, M.; Palma-Behnke, R.; et al. Trends in microgrid control. IEEE Trans. Smart Grid 2014, 5, 1905-1919. [CrossRef]

124. Arriaga, M.; Cañizares, C.A.; Kazerani, M. Long-Term Renewable Energy Planning Model for Remote Communities. IEEE Trans. Sustain. Energy 2016, 7, 221-231. [CrossRef]

(C) 2019 by the authors. Licensee MDPI, Basel, Switzerland. This article is an open access article distributed under the terms and conditions of the Creative Commons Attribution (CC BY) license (http://creativecommons.org/licenses/by/4.0/). 